\title{
Breast-Conserving Therapy Versus Modified Radical Mastectomy in the Early Breast Cancer Management: Oncological Outcome and Quality of Life
}

\author{
HALA A. EL-MAGHAWRY, M.D.*; MOHAMED F. AMIN, M.D.**; MOSTAFA M. KHAIRY, M.D.**; \\ AHMED S. ARAFA, M.D.**; HANAA A. NOFAL, M.D.*; ABD EL-MOTALEB MOHAMED, M.D.*** and \\ AHMED EL-AZONY, M.D.*** \\ The Departments of Community, Environmental \& Occupational Medicine*, General Surgery**and Clinical Oncology***, \\ Faculty of Medicine, Zagazig University, Egypt
}

\begin{abstract}
Background: Breast cancer is the most common malignancy among women. Mastectomy is the current standard surgical procedure for ipsilateral tumor of the breast. However, there is little evidence about the prognostic effect of the surgical procedure (mastectomy versus lumpectomy) for early management of breast cancer. We investigated the breastconserving therapy versus radical mastectomy in the early breast cancer management, and investigated the effect of treatment modalities on quality of life after breast cancer surgery.
\end{abstract}

Aim of Study: To investigate the oncological outcomes of Breast-Conserving Therapy (BCT) versus Radical Mastectomy (MRM) in the early breast cancer management and to investigate the effect of treatment modalities on Quality of Life (QOL) more than 1 year after breast cancer surgery by comparing the QOL of the two groups of patients who underwent Breast Conserving Surgery (BCS) or Modified Radical Mastectomy (MRM).

Patients and Methods: A retrospective-prospective cohort study between June 2010 and June 2017, at Zagazig University Hospitals in the General Surgery and Oncology Departments, a group of 456 patients (295 patients in the BCT group, 161 patients in the MRM group) was selected. Of the 456 patients enrolled, 383 patients gave their consent and completed the study questionnaire (177 patients in the BCT group, and 206 patients in the MRM group.

Results: After 2-6years of follow-up, the overall survival was lower for BCT group 93.9\%. While in MRM group was 94.4\% with no statistical difference between both groups regarding this parameter. Quality of life after BCT was found better than MRM in the social and the emotional functions.

Conclusions: The breast-conserving-therapy has been shown to be as effective as mastectomy in the treatment of early breast cancer in the local recurrence and overall survival

Correspondence to: Dr. Hala Ahmed El-Maghawry, E-Mail: halamf@yahoo.com rate of those patients. BCT improves the patients' QOL more than MRM does.

Key Words: Breast cancer-Conservative therapy - Radical mastectomy - Quality of life.

\section{Introduction}

BREAST cancer is thought to be the commonest and the most fatal female cancer in the world. The incidence and severity of such type of cancer continue to increase although there is improvement in the clinical outcome and patients' prognosis due to advances in therapies strategies recently this point to an urgent need for finding new therapies to identify patient prognosis and improve treatment strategies [1].

Surgical treatment of breast cancer has changed significantly over time. Today they do more than just remove the tumor where they are the patient's first contacts, leaders of a multidisciplinary team, guiding the patient through the many diagnostic and therapeutic modalities comprising the modern management of the breast cancer [2] .

Until the mid-1980, the surgical treatment for stage I or II breast cancer was modified radical mastectomy since then, evidence from randomized trials has shown that Breast-Conserving Surgery (BCS) with radiotherapy; Breast Conserving Therapy (BCT) produces results equivalent to those obtained with modified radical mastectomy in terms of survival. These results have led to the adoption of BCT as the treatment of choice for patients with early breast cancer [3] 
In the developed countries, BCT is recommended as the standard treatment for most patients with early breast cancer. Breast conservation involves resection of the primary breast cancer with a margin of normal-appearing breast tissue (lumpectomy), axillary clearance and adjuvant radiation therapy. Post-operative irradiation of the remaining breast tissue represents an integral part of BCT to decrease the risk of local recurrences [4].

Several randomized European and North American studies compared various aspects of conservative surgery and modified radical mastectomy over 10 years. They all confirmed almost identical survival after these two treatment options [5] Regarding hypofractionated regimens in breast cancer stems, the majority of breast tumors have a relatively low $\mathrm{a} / \mathrm{p}$ ratio of $3 \mathrm{~Gy}$ and are therefore more sensitive to fraction size than to total dose. To correlate with the use of higher dose per fraction, total radiation doses are lowered with hypofractionated regimens, and it is total dose that is expected to correlate with acute toxicities [6].

Evaluation of quality of life is important in chronic diseases; it is a better indicator of patients' function and well-being compared to the physicians' clinical and para-clinical indices [7]. Radical breast cancer surgery is commonly used for surgery methods that may have destruction on pretty figure of breast and a serious impact on the Quality of Life of patients (QOL), while breast conservation has advantages such as breast retention, which meets the life requirements of patients [8]. Therefore, one of the purposes of this study was to compare the effect of the two methods on Quality of Life (QOL).

\section{Rational:}

Breast cancer is the most common malignancy among women, and the majority of patients will present with earlystage disease. Mastectomy is the current standard surgical procedure for ipsilateral tumor of the breast. However, there is little evidence about the prognostic effect of the surgical procedure (mastectomy versus lumpectomy) for early management of breast cancer. Several clinical trials have established the oncologic inequality of the different treatment options available to these patients; however, each treatment approach is associated with different outcomes and quality of life. To our knowledge, there are no recent studies that directly compare survival, quality of life after Breast Conservation Therapy (BCT) Vs. mastectomy.

\section{Material and Methods}

Study design and patients:

A retrospective-prospective cohort study between June 2010 and June 2017, out of all surgically treated patients at Zagazig University Hospitals in the General Surgery and Oncology Departments, all patients with clinical stage I and II breast cancer (T1 and T2, diameter up to $5 \mathrm{~cm}, \mathrm{~N} 0$ and $\mathrm{N} 1, \mathrm{M} 0$ ) were included in the study (456 patients).

\section{The inclusion criteria:}

1- Adenocarcinoma of the breast, stage T1-2, N0 and M0.

2- Received therapy at Zagazig University Hospitals in the General Surgery and Oncology Departments between June 2010 and June 2017.

3- Complete data.

4- Without recurrence and metastases.

Treatment included surgery to remove the tumor (either BCT or MRM) and/or radiotherapy and/or chemotherapy and/or hormone treatment.

The exclusion criteria:

1- Multicentric disease.

2- Advanced or metastatic disease.

3- Concomitant or previous ipsilateral or contralateral breast cancer.

4- Pregnant or lactating.

Tools of the study:

1-Routine investigations: Bilateral mammography, chest X-ray, pelviabdominal ultrasound and full blood count were done routinely for patients. Baseline echocardiography was done for elderly patients and human epidermal growth factor receptor 2 (HER2+) patients prior to initiation of trastuzumab therapy (monoclonal antibody used to treat breast cancer).

2- Short Form-36 (SF-36) questionnaire were used to evaluate the quality of life of the patients (QOL), including 8 items such as physical function, role physical function, physical pain, general health, vital energy, social function, emotional function and mental health [9].

\section{Techniques:}

Data were extracted from the patients' medical records were: Type of surgery, patient age, menopausal status, side of breast cancer, nodal status, TNM staging (7 th ed) [10], receptor (estrogen, progesterone, HER2) status, tumor size, histopathology grade, lympho-vascular invasion. The 
included patients were treated either with modified radical mastectomy plus axillary dissection or conservatively (quadrentectomy, axillary dissection and radiation therapy). Out of 456 patients included, 161 belonged to the mastectomy group (the 1 st group) treated with modified radical mastectomy operation of Patey with axillary dissection (I, II floor lymph nodes), and 295 to the conservative treatment group (the 2 nd group) treated conservatively with quadrentectomy (excision of $2-3 \mathrm{~cm}$ of normal tissue around the tumor plus the removal of a sufficiently large portion of overlying skin and underlying fascia). All patients gave their informed consent before inclusion in the study. Level I, II axillary dissection was performed.

Modified Radical Mastectomy (MRM): Preoperative conventional imaging was adopted to determine the location of cancer and tumor size. Then according to the breast shape and different sizes, transverse or longitudinal spindle incision was selected. The incision should have a distance of more than $3 \mathrm{~cm}$ to the edge of the tumor.

Breast conserving surgery $(B C T)$ : Same as the radical group, imaging location was used to determine the foci location and size in conserving group. According to breast shape and different sizes, transverse or longitudinal spindle incision was selected. The incision should have a distance of more than $2 \mathrm{~cm}$ to the edge of the tumor. With conventional complete resection of about $2 \mathrm{~cm}$ normal tissue of the tumor margin, tissue above the tumor generally was kept. Suture markers and intraoperative frozen section were performed on 5 directions (inside, outside, top, bottom and the base) of tumor edge to ensure negative margins. If biopsy showed positive margins, expansion of resection should be done in the according side. If the margin was still positive after expansion, modified radical surgery was required. Incision suture was operated after all margins became negative. Stump gland of both sides should not be sutured to avoid the abnormal appearance of post-operative breast shape.

Regarding adjuvant systemic therapy, all patients with node positive or high-risk node-negative tumors received adjuvant chemotherapy in the form of FAC protocol (5-fluorouracil, Adriamycin and cyclophosphamide) for 6 cycles every 3 weeks or 4AC + Taxol protocol. None of the patients underwent neoadjuvant chemotherapy. All HER2+ patients received adjuvant trastuzumab therapy for 1 year. Adjuvant hormonal therapy was administered for hormone receptor-positive tumors using tamoxifen or aromatase inhibitors with or without goserelin according to menopausal status.

Regarding post-lumpectomy radiotherapy, the current study used Whole Breast Irradiation (WBI) with conventional wedged photon tangents designed with either conventional fluoroscopic or CT-based simulation. Radiation field was limited to breast only if the nodes were negative. Regional nodal radiotherapy was given if the axillary nodes were positive. The internal mammary nodes were included for central or inner quadrant lesions. Wedges were used to establish a homogenous dose distribution to the target volume within $-5 \%$ and $+7 \%$ while keeping a maximum lung depth $<2.5 \mathrm{~cm}$. Field-in-field techniques were used. Most patients were treated by a $6 \mathrm{MV}$ linear accelerator, with higher energies used in patients with larger separations. The boost (prescribed to the $90 \%$ reference isodose) was delivered with 6 to $12 \mathrm{MeV}$ appositional electron field.

At earlier years of the study, the dose was 50Gy in 25 fractions in 5 weeks (2Gy per fraction) followed by a boost dose $1000 \mathrm{cGy} / 5$ fractions to the tumor bed. Later, the institution protocol was changed to a more hypofractionated regimen (40Gy in 15 daily fractions (2.67Gy per fraction) followed by a sequential boost in an attempt to improve efficiency, delivery of care costs and patient logistics. The current study also compared these two fractionation regimens with regard acute and late toxicity.

The indications for Post-Mastectomy Radiotherapy (PMRT) included tumor size equal $5 \mathrm{~cm}$ and/or 1-3 positive lymph nodes with adverse pathology or age less than 40 years. Post-mastectomy radiotherapy included the chest wall and regional nodes. Only minority of patients received PMRT and all with conventional fractionation 50 Gy in 25 fractions in 5 weeks (2Gy per fraction).

After finishing radiotherapy, patients were followed with breast examinations every 3 months during the first 2 years, every 4-6 months from year 2 to year 5 , and annually thereafter. Followup included a clinical examination at every time point, plain chest X-ray, pelviabdominal ultrasound and mammography once a year, complete blood cell count and tumor markers twice a year; other radiological examinations were performed when needed. In the current study, loco-regional recurrence means tumour recurrence in either the ipsilateral breast or lymph nodes. Overall Survival (OS) is defined from the time of surgery to the 
date of the last follow-up/death of the patients. Acute breast skin toxicity was assessed during each week of radiation and at one month and 3 months after radiation treatment. Late toxicity was defined as toxicity from 6 months after the end of $\mathrm{RT}$ and thereafter.

Oncological outcome assessment: The local recurrence rate, distant metastasis rate and $5 y$ survival rate of patients after operation were compared according to the follow-up data.

Quality of life assessment (QOL): Of the 456 patients enrolled, 73 patients were excluded from the study either due to refusing further participation or due to presence of impaired cognitive function (67 in the BCT group and 6 in the MRM group). The remaining 383 patients (they were medically stable at least 1 year after surgery and finished breast cancer treatment) gave their consent and completed the study questionnaire. There were 177 patients in the BCT group (47.4\% with stage I and $52.6 \%$ with stage II breast cancer), and 206 patients in the MRM group (58.7\% with stage I and $41.3 \%$ with stage II breast cancer). After obtaining the consent, the SF-36 QOL questionnaire was administered to the subjects during their follow-up visits. All women were instructed to complete the questionnaire themselves. patients who were unable to read and completed the form completed with the help of their relatives. Patients completed the questionnaires at the outpatient clinic visit. Patients were interviewed face-to-face at the outpatient clinic visit. The questionnaire was used by its Arabic version [11].

The eight scales of the SF-36 include the following:

1-Physical Functioning (PF): Ten questions that ask the extent to which health limits the performance of physical activities.

2- Role-Physical (RP): Role limitations due to physical health problems; four questions that ask individuals the extent to which their physical health limits them in their work or other usual activities in terms of time and performance.

3- Bodily Pain (BP): Two questions that ask individuals about the severity of their pain and the extent to which pain interferes with normal work, including work outside the home and housework.

4- General Health (GH): Five questions that ask individuals to rate their current health status overall, their susceptibility to disease, and their expectations for health in the future.
5- Vitality (VT): Four questions that ask individuals to rate subjective well-being in terms of energy and fatigue.

6- Social Functioning (SF): Two questions that ask individuals about limitations in normal social functioning due specifically to health.

7- Role-Emotional (RE): Role limitations due to emotional problems; three questions that ask whether emotional problems have interfered with accomplishments at work or other usual activities in terms of time as well as performance.

8- Mental Health (MH): Five questions that ask how frequently the respondent experiences feelings related to anxiety, depression, loss of behavioral or emotional control, and psychological well-being. The total score for each subscale was computed and recoded according to the SF36 Health Survey Manual and Interpretation Guide. The higher score indicated the better quality of life [9].

\section{Ethical approval:}

This study was reviewed and approved by Institutional Review Board (IRB) for medical research ethics, Zagazig University, Faculty of Medicine prior to implementation of the study (ZU-IRB 5072). An official approval for the implementation of the study was obtained from General Surgery and Oncology Departments, Zagazig University. The study participants were informed about the nature and the purpose of the study, verbal consent was taken before interview. The study participants were not be exposed to any harm or risk. Data was confidential.

\section{Statistical design and data management:}

Data entry was performed using the Statistical Package for Social Sciences (SPSS ver. 16) [12] Continuous data are expressed as the mean $\pm S D$, and the categorical data are expressed as a number (percentage). Evaluation of the statistical significance differences in the categorical data between groups were performed using the Chi-square $\left(\chi^{2}\right)$ test. Distributions of the continuous variables were analyzed by the Student $t$-test $(t)$ for two groups of normally distributed data. Overall Survival (OS) was estimated using the Kaplan-Meier survival curve. Mean and standard deviations were calculated for items of SF-36 QOL questionnaire and tested by independent $t$-test for the comparison between two groups. Null hypotheses of no difference were rejected if $p$-values were less than 0.05 . 


\section{Results}

Basic characteristics of the two studied groups:

Mean age of female in BCT group was insignificantly different from mean age of female in MRM group (39.8 \pm 7.3 Vs. $40.6 \pm 8.7, p=0.16$ ). There were no statistically significant differences in memopausal status, tumor sizes, receptors status (Estrogen, Progesterone and HER2), histopathology grade and lympho-vascular invasion $(p>0.05)$ (Table 1).

The total number for occurance of recurrence in the MRM group was 34 patients. In 5 patients $(14.7 \%)$ out of 34 treated with modified radical mastectomy, the local recurrence occurred at the excision site. Comparing the frequency of local recurrence after modified radical mastectomy with recurrences after conservative surgery, no statistically significant difference was found $(14.7 \% \mathrm{Vs}$. $23.8 \%, p=0.2$ ) (Table 2).

After 2-6 years of follow-up, the overall survival was lower for BCS group 93.9\%. While in MRM group was $94.4 \%$ with no statistical difference between both groups regarding this parameter $(\chi$ 0.079, $p$-value 0.779) Fig. (1).

Radiation-related skin toxicity regarding acute reactions, most of the toxicity was grade 1 in both radiotherapy groups $(57.7 \%$ in Conventionallyfractionated (CF) group Vs. 61.4\% in Hypofractionated (HF) group). While grade 2 skin reaction was seen in $34.5 \%$ of $(\mathrm{CF})$ group Vs. $29.1 \%$ of (HF) group. Only $4.2 \%$ of (CF) group and $3.9 \%$ of (HF) group show grade 3 toxicity. None of the patients in both groups show grade 4 toxicity (Table 3 ).

Regarding late toxicity, $28.6 \%$ of (CF) group developed fibrosis of the treated breast Vs. 32.3\% of (HF) group with no statistical difference between both groups. Similarly, $4.8 \%$ of (CF) group patients developed skin teleangectasia Vs. 5.5\% of (HF) group $(p>0.05)$ (Table 4).

SF-36 was used for the evaluation of life quality of patients during the follow-up period. Quality of life after BCT was found better than MRM in the social and the emotional functions. In the total quality of life evaluation according to the total score; it was found to be significantly better in the BCS group than MRM patients. However, the differences between two groups was not statistically significant in regards to the physical function and general health (Table 5).
Table (1): Basic clinico-pathological data of the studied groups $(\mathrm{N}=456)$.

\begin{tabular}{|c|c|c|c|}
\hline $\begin{array}{l}\text { Clinico-pathological } \\
\text { data }\end{array}$ & $\begin{array}{l}\text { BCT group } \\
(\mathrm{n}=295)\end{array}$ & $\begin{array}{l}\text { MRM group } \\
\quad(\mathrm{n}=161)\end{array}$ & $\begin{array}{c}p- \\
\text { value }\end{array}$ \\
\hline Age range: & $(30-56)$ & $(27-63)$ & \\
\hline$<40$ years & $93 \quad(31.5)$ & $42 \quad(26)$ & 0.16 \\
\hline$>40$ years & $202(68.5)$ & $119(74)$ & \\
\hline Mean age & $39.8 \pm 7.3$ & $40.6 \pm 8.7$ & \\
\hline \multicolumn{4}{|l|}{ Side of breast cancer: } \\
\hline Right & $191(64.7)$ & $88(54.6)$ & 0.03 \\
\hline Left & $104(35.3)$ & $73(45.4)$ & \\
\hline \multicolumn{4}{|l|}{ Menopausal status: } \\
\hline Pre-menopausal & $147(49.8)$ & $72(44.7)$ & 0.29 \\
\hline Post-menopausal & $148(51.2)$ & $89(55.3)$ & \\
\hline \multicolumn{4}{|l|}{ Tumor size: } \\
\hline $\mathrm{T} 1(\leq 2 \mathrm{~cm})$ & $38 \quad(12.9)$ & $12(7.45)$ & 0.07 \\
\hline $\mathrm{T} 2(2-5 \mathrm{~cm})$ & $257(87.1)$ & $149(92.55)$ & \\
\hline \multicolumn{4}{|l|}{ Nodal status: } \\
\hline No & $159(53.9)$ & $63(39.1)$ & 0.01 \\
\hline N1 & $136(46.1)$ & $98(60.9)$ & \\
\hline \multicolumn{4}{|l|}{ TNM staging: } \\
\hline Stage I & $36 \quad(12.2)$ & $10 \quad(6.2)$ & 0.04 \\
\hline Stage II & $259(87.8)$ & $151(93.8)$ & \\
\hline \multicolumn{4}{|c|}{ Estrogen receptor status: } \\
\hline Positive & $273(92.5)$ & $142(88.1)$ & 0.12 \\
\hline Negative & $22(7.5)$ & 19 (11.9) & \\
\hline \multicolumn{4}{|c|}{ Progesterone receptor } \\
\hline \multicolumn{4}{|l|}{ status: } \\
\hline Positive & $263(89.1)$ & $137(85)$ & 0.2 \\
\hline Negative & $32 \quad(10.9)$ & $24 \quad(15)$ & \\
\hline \multicolumn{4}{|l|}{ HER2 status: } \\
\hline Positive & $79 \quad(26,8.4)$ & $36 \quad(22.4)$ & 0.2 \\
\hline Negative & $216(73.2)$ & 125 (77.6) & \\
\hline \multicolumn{4}{|l|}{ Histopathology grade: } \\
\hline Grade I & $68 \quad(23)$ & $40(24.8)$ & 0.3 \\
\hline Grade II & $191(64.7)$ & $94(59.3)$ & \\
\hline Grade III & $36 \quad(12.2)$ & 27 (16.7) & \\
\hline \multicolumn{4}{|l|}{ Lympho-vascular } \\
\hline \multicolumn{4}{|l|}{ invasion: } \\
\hline Yes & $139(47.1)$ & 79 (49) & 0.6 \\
\hline No & $156(52.9)$ & $82(51)$ & \\
\hline \multicolumn{4}{|l|}{$\begin{array}{l}\text { Safety margin of } \\
\text { resection: }\end{array}$} \\
\hline $1-5 \mathrm{~mm}$ & $17 \quad(5.7)$ & (3.7) & 0.06 \\
\hline $5 .-10 \mathrm{~mm}$ & $35 \quad(11.8)$ & $9 \quad(5.6)$ & \\
\hline$>10 \mathrm{~mm}$ & $243(82.3)$ & $146(90.6)$ & \\
\hline
\end{tabular}


Table (2): Pattern of recurrence in both treatment groups.

\begin{tabular}{|c|c|c|c|}
\hline Type of recurrence & $\mathrm{BCT}$ & MRM & $p$-value \\
\hline Local & $16(23.8)$ & $5 \quad(14.7)$ & 0.2 \\
\hline Regional & $6 \quad(8.9)$ & $2 \quad(5.8)$ & 0.5 \\
\hline Distant & $41(61.2)$ & $24(70.5)$ & 0.3 \\
\hline Local and regional & $3 \quad(4.4)$ & $1 \quad(2.9)$ & 0.7 \\
\hline Local and distant & $2(2.9)$ & $1 \quad(2.9)$ & 0.9 \\
\hline Regional and distant & $7 \quad(10.4)$ & $3 \quad(8.8)$ & 0.7 \\
\hline Total & $67(100.0)$ & $34(100.0)$ & 0.6 \\
\hline
\end{tabular}

Table (3): Acute radiation-related skin toxicity $(n=295)$.

\begin{tabular}{llllll}
\hline Grade & $\begin{array}{c}\text { Conventional } \\
\text { fractionation } \\
(\mathrm{n}=168)\end{array}$ & $\begin{array}{c}\text { Hypofractionation } \\
(\mathrm{n}=127)\end{array}$ & $\begin{array}{c}p \text { - } \\
\text { value }\end{array}$ \\
\hline No. & $\%$ & No. & $\%$ & \\
\hline Grade 0 & 6 & 3.6 & 7 & 5.5 & $>0.05$ \\
Grade 1 & 97 & 57.7 & 78 & 61.4 & \\
Grade 2 & 58 & 34.5 & 37 & 29.1 & \\
Grade 3 & 7 & 4.2 & 5 & 3.9 & \\
Grade 4 & 0 & 0 & 0 & 0 & \\
\hline
\end{tabular}

Table (4): Late radiation-related skin toxicity $(n=295)$.

\begin{tabular}{|c|c|c|c|c|c|}
\hline \multirow[t]{2}{*}{ Toxicity } & \multicolumn{2}{|c|}{$\begin{array}{l}\text { Conventional } \\
\text { fractionation } \\
\qquad(\mathrm{n}=168)\end{array}$} & \multicolumn{2}{|c|}{$\begin{array}{l}\text { Hypofra- } \\
\text { ctionation } \\
(\mathrm{n}=127)\end{array}$} & \multirow[t]{2}{*}{$\begin{array}{c}p- \\
\text { value }\end{array}$} \\
\hline & No. & $\%$ & No. & $\%$ & \\
\hline \multicolumn{6}{|c|}{ Hyperpigmentation: } \\
\hline Yes & 57 & 33.9 & 36 & 28.3 & $>0.05$ \\
\hline No & 111 & 66.1 & 91 & 71.7 & \\
\hline \multicolumn{6}{|c|}{ Fibrosis/induration: } \\
\hline Yes & 48 & 28.6 & 41 & 32.3 & \\
\hline No & 120 & 71.4 & 86 & 67.7 & \\
\hline \multicolumn{6}{|c|}{ Telangiectasia: } \\
\hline Yes & 8 & 4.8 & 7 & 5.5 & \\
\hline No & 160 & 95.2 & 120 & 94.5 & \\
\hline \multicolumn{6}{|c|}{ Breast Edema: } \\
\hline Yes & 13 & 7.7 & 8 & 6.3 & \\
\hline No & 155 & 92.3 & 119 & 93.7 & \\
\hline \multicolumn{6}{|c|}{ Lymphedema: } \\
\hline Yes & 11 & 6.5 & 10 & 7.9 & \\
\hline No & 157 & 94 & 117 & 92.1 & \\
\hline
\end{tabular}

Table (5): Comparison of quality of life of patients in the two groups.

\begin{tabular}{lllll}
\hline Items & $\begin{array}{c}\text { BCT } \\
(\mathrm{n}=177)\end{array}$ & $\begin{array}{c}\text { MRM } \\
(\mathrm{n}=206)\end{array}$ & $\begin{array}{c}t \text { - } \\
\text { value }\end{array}$ & $\begin{array}{c}p \text { - } \\
\text { value }\end{array}$ \\
\hline Physical function & $19.1 \pm 5$ & $19.4 \pm 5$ & -0.529 & 0.298 \\
Role physical function & $5.8 \pm 1.4$ & $5.7 \pm 1.4$ & 0.14 & 0.44 \\
Bodily pain & $5.9 \pm 2.6$ & $6 \pm 2.6$ & -0.37 & 0.35 \\
General health & $12.8 \pm 6.3$ & $12.9 \pm 6.1$ & -0.156 & 0.437 \\
Vitality of life & $9.3 \pm 5.4$ & $9.5 \pm 5.8$ & -0.337 & 0.368 \\
Social function & $6.8 \pm 1.7$ & $3.9 \pm 2.7$ & 12.1 & 0.001 \\
Emotional function & $5.2 \pm 0.8$ & $3.6 \pm 0.7$ & 19.4 & 0.001 \\
Mental health & $10.2 \pm 6.7$ & $10.1 \pm 6.8$ & -0.149 & 0.44 \\
\hline Total score & $75.1 \pm 14.1$ & $71.3 \pm 11.7$ & 2.87 & 0.002 \\
\hline BCT : Breast Conservative Therapy. & & & \\
MRM : Modified Radical Mastectomy. & & & \\
\end{tabular}

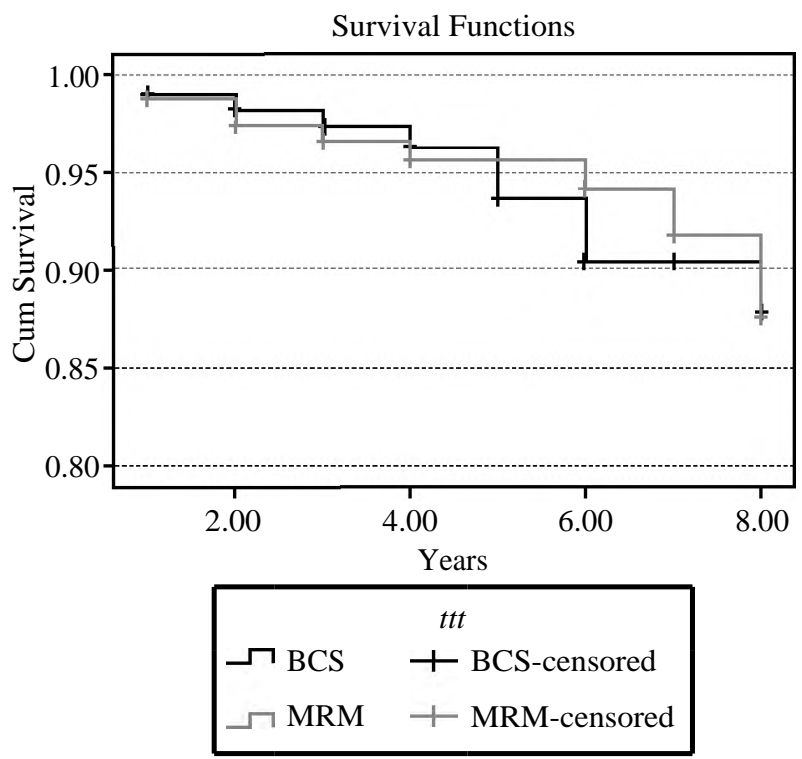

Fig. (1): Kaplan-Meier survival analysis shows no significant stastical difference in 5-year survival between BCS and MRM groups.

\section{Discussion}

Breast Conserving Surgery (BCS) with radiation therapy is today standard therapy for low grade Breast Cancer. It is safe and preferred therapeutic procedure in all early detected breast cancers, because it provides the same level of overall survival as mastectomy. Same survival rates as seen in patients treated with mastectomy, have been found by several prospective and randomized studies and number of clinical trials [13].

In the current study, we evaluated the impact of the surgical procedures (BCT versus MRM) on Overall Survival (OS).

In the present study, from patients who underwent surgery for breast cancer at Zagazig University Hospitals, we found that $64.6 \%$ (295 patients) 
received BCT with mean age $(39.8 \pm 7.3)$. There was no statistically significant difference from mean age of females in MRM group $(p<0.005)$. This is in line with a study in the United States reported that, among women with early stage (I or II) breast cancer, $58 \%$ underwent $\mathrm{BCT}$ and $42 \%$ MRM [14]. However these results are inconsistence with a study in South Africa that reported $72 \%$ of women with early stage breast cancer underwent TM and only $28 \%$ received BCS [15]

As regarding histo pathological charactaristics (tumor sizes, receptors status (Estrogen, Progesterone and HER2), histopathology grade and Lymphovascular invasion), there were no statistically significant differences between the two groups ( $p$ $>0.05$ ) (Table 1). This is in line with several studies referring to the prognostic impact of the surgical procedures (repeat lumpectomy versus mastectomy). They showed no difference in the prognosis between repeat lumpectomy and mastectomy [16]

Regarding local recurrence, the incidence of Local Recurrence (LR) was higher in the BCT group than in the MRM group (23.8\% Vs. 14.7\%), but this difference was not statistically significant $(p=0.2)$ (Table 2). This is consistent with a study in China that reported that the difference between the BCT and the MRM groups was not statistically significant $(p=0.182)$ [1]

Regarding overall survival, the 5 year overall survival in these groups was $93 \%$ (95\% CI: 7.47.8) for the patients assigned to breast conservative therapy group and $94.4 \%$ (95\% CI: 7.4-7.9), for those assigned to mastectomy group with no statistically significant difference $(p>0.005)$ Fig. (1). This is in contrast with a study that reported the 6-year DFS rates in these groups were $91.3 \%$ (95\% CI: 0.894-0.932) and 86.3\% (95\% CI: 0.840-0.886), respectively with statistically significant difference $(p<0.001)$ [1].

Adjuvant WBI is generally well tolerated, but mild acute skin toxicity is a frequent side effect. In the present study, the great majority of patients experienced mild (G1) to moderate (G2) acute skin reaction in the form of erythema and dry desquamation respectively. Only minority of patients show moist desquamation (G3) along with the lack of severe (grade 4) toxicity (Table 3 ). These results coincide with the existing literature and emphacize the findings of multiple randomized trials comparing conventionally fractionated versus hypofractionated regimens in patients being treated with adjuvant RT to the intact breast. These trials have demonstrated equivalent long-term outcomes, with improved acute and late toxicities in the hypofractionated arms [17]. Following breast irradiation, fibrosis and teleangectasia are of the most common late adverse effects. Fibrosis/induration occurrence is highest during the first few years after radiotherapy and then plateaus while teleangectasia follow a progressive course at least up to 10 years after end of radiotherapy (Table 4). The rate of fibrosis in the present study was not statistically different between both radiation groups. The risk of fibrosis appear to be related to the maximum dose ( $\left.\mathrm{D}_{\max }\right)$ administered during breast irradiation rather than volume parameters [18]

In particular, our analysis revealed that some benefts of BCT, is a better body image, and are already visible after completion of therapy, specially benefts in psychosocial well-being and overall quality of life. In relation to the SF-36 QoL scores between the BCT and the MRM groups regarding the physical, role of physical functions, bodily pain, general heath, vitality and mental functions there were no statistically significant differences between the two groups of the study (Table 5). This is consistent with study in Michigan that reported there was not a remarkable different in QoL as compared BCT to MRM as might have been expected specially in the physical functions, pain, general heath and mental functions [19]. Also results of study on breast cancer survivors indicated that there were no significant differences between the groups on physical and mental health [20] However, this finding is in contrast with studies that found, life quality (in all its domains) of conserving group (BCT) was significantly better than that of the radical group (MRM) $(p$ $<0.05)$ [21]

Concerning the social function, the scores of the $\mathrm{BCT}$ group were higher than those of the MAS group. These findings indicate that BCT patients received more encouragement from their friends and relatives. Similar results were found in a study stated that in the social domain, the scores of the BCT group were higher than those of the MRM group [22]. In particular, the scores of the statements "I get support from my friends" and "I get emotional support from my family". This is in line with study that reported life quality of conserving group (BCT) was significantly better than that of the radical group (MRM) $(p<0.05)$ concerning the social domain [21].

As regarding the emotional functions, the scores of the BCT group were higher than those of the MAS group. These findings may be explained by the fact that patient who perceived breast appear- 
ance after BCT is significantly associated with more emotional stability, and women with pronounced breast asymmetry are more likely to experience poor emotional functioning compared with women with minimal breast asymmetry. Similar results were found in a study reported that in the emotional domain, the scores of the BCT group were higher than those of the MRM group. In particular, the scores of the statements "cut down the amount of time spent on work or other outdoor activities" [22]. Also other study found that life quality of conserving group (BCT) was significantly better than that of the radical group (MRM) $(p$ $<0.05$ ) concerning the emotional domain [23] .

Talking about the total QOL score, the current study revealed that the total QoL scores were statistically significant different between BCT and MRM patients $(\mathrm{p}<0.05)$ it may be explained by the fact that surgery modality have a notable impact on social and emotional QoL domains, as breast conserving surgery preserve a positive body image, will not compromise patients' trust and will enhance patients' overall satisfaction with their treatment. this is consistent with Cui who found that the average score of life quality of conserving group (BCT) was significantly better than that of the radical group (MRM) [21]. This is in contrast to a study in Netherlands that reported that the total QoL scores were not significantly different between $\mathrm{BCT}$ and MAS patients [24].

\section{Conclusion:}

Considering the aspects evaluated in this study, we can concluded that the breast-conserving therapy has been shown to be as effective as mastectomy in the treatment of early breast cancer. Long term follow-up also shows no stastically significant difference between breast conserving surgery and modified radical mastectomy in the local recurrence and overall survival rate of those patients. Also, hypofractionation scheme is feasible and well tolerated and offers women WBI in a highly convenient schedule. In conclusion about QOL, the SF measures would provide a useful aide for health care providers to assess health-related outcomes of breast cancer survivors in their care. The results of the present study suggest that BCT improves the patients' QOL more than MRM does.

\section{Recommendations:}

The patients receiving MRM require more social and emotional support than those receiving BCT during the early postoperative period. Future research could look at establishing invariance of the SF-36 between breast cancer survivors and healthy women. Such findings would be useful in deter- mining the true impact of this illness on long term cancer survivors by allowing comparisons of QoL with healthy individuals. This could be a logical step in determining the needs and steps necessary for individuals who have gone through a life changing experience to benefit from optimal QoL.

\section{Conflict of interest:}

The authors declare that they have no competing interests.

\section{References}

1- WANG L., OUYANG T., WANG T., XIE Y., FAN Z., LIN B. and LI J.: Breast-conserving therapy and modified radical mastectomy for primary breast carcinoma: A matched comparative study. Chin. J. Cancer Res., 27 (6): 545-52, 2015

2- ANGELO G., RENE A. and RODRIGO A.: The development of an Oncoplastic Training Center-OTC. Int. J. Surg., 10: 265-9, 2012.

3- RIEDEL F., HENNIGS A., HUG S., SCHAEFGEN B., SOHN C., SCHUETZ F., GOLATTA M. and HEIL J.: Is Mastectomy Oncologically Safer than Breast-Conserving Treatment in Early Breast Cancer? Breast Care (Basel), Dec., 12 (6): 385-90, 2017.

4- EDWARD M. and KIRBY I.: The breast. In Schwartz's Principles of Surgery. ${ }^{9^{\mathrm{th}}}$ ed. Brunicardi F, McGraw-Hill Companies, Inc., Vol. 2 (17): p. 882-3, 2010.

5- KAVIANI A., SODAGARI N., SHEIKHBAHAEI S., ESLAMI V., HAFEZI-NEJAD N., SAFAVI A., et al.: From Radical Mastectomy to Breast-Conserving Therapy and Oncoplastic Breast Surgery: A Narrative Review Comparing Oncological Result, Cosmetic Outcome, Quality of Life, and Health Economy. ISRN Oncol., 2013: 742462. Published online 2013 Sep. 12. Doi: 10.1155/ 2013/742462, 2013.

6- HAVILAND J.S., OWEN J.R., DEWAR J.A., et al.: The UK standardization of breast radiotherapy (START) trials of radiotherapy hypofractionation for treatment of early breast cancer: 10-year follow-up results of two randomised controlled trials. Lancet Oncol., 14: 1086-94, 2013.

7- HADI N., SOLTANIPOUR S. and TALEI A.: Impact of Modified Radical Mastectomy on Health-related Quality of Life in Women with Early Stage Breast. Arch. Iran med, 15 (8): 504-7, 2012.

8- SUN D.: Effect of breast conserving surgery and radical surgery on early-stage breast cancer in elderly patients and its effect on complications and quality of life. Chin. J. Gerontol., 34: 3173-4, 2014.

9- WARE J., KOSINSKI M. and GANDEK B.: SF-36 health survey: Manual \& interpretation guide. Lincoln, RI: Quality Metric Incorporated, P. 1993-2000, 2005.

10- HELAL M.H., MANSOUR S.M., ZAGLOL M., SALALELDIN L.A., NADA O.M. and HAGGAG M.A.: Staging of breast cancer and the advanced applications of digital mammogram: What the physician needs to know? Br. J. Radiol., 90 (1071): 1090, 2017.

11-AL-ABDULMOHSIN S.A., COONS S.J. and HAYS R.D.: Translation of the RAND 36-ITEM Health Survey 1.0 
(aka SF-36) into Arabic. RANDS URL (https://www.rand. org/pubs/papers/P7995.html), 1997.

12- SPSS Inc.: Released. SPSS for Windows, Version 16.0. Chicago, SPSS Inc, 2007.

13-FAJDIC J., DJUROVIC D., GOTOVAC N. and HRGOVIC Z.: Criteria and Procedures for Breast Conserving Surgery, Acta Inform. Med., 21 (1): 16-9, 2013.

14- DeSANTIS C.E., LIN C.C., MARIOTTO A.B., SIEGEL R.L., STEIN K.D., KRAMER J.L., ALTERI R., ROBBINS A.S. and JEMAL A.A.: Cancer treatment and survivorship statistics, 64 (4): 252-71, 2014.

15- CUBASCH H., JOFFE M., RUFF P., DIETZ D., ROSENBAUM E., MURUGAN N., et al.: Breast conservation surgery versus total mastectomy among women with localized breast cancer in Soweto, South Africa. PLoS ONE, 12 (8): 1: 13, 2017.

16- FODOR J., MAJOR T., POLGAR C., OROSZ Z., SULYOK Z. and KASLER M.: Prognosis of patients with local recurrence after mastectomy or conservative surgery for early-stage invasive breast cancer. Breast, 17: 302-8, 2008.

17- SHAITELMAN S.F., SCHLEMBACH P.J., ARZU I., et al.: Acute and short-term toxic effects of conventionally fractionated vs hypofractionated wholebreast irradiation: A randomized clinical trial. JAMA Oncol., 1: 931-41, 2015.

18- HAMILTON D.G., BALE R., JONES C., FITZGERALD E., KHOR R., KNIGHT K., et al.: Impact of tumour bed boost integration on acute and late toxicity in patients with breast cancer: A systematic review. Breast, 27: 12635, 2016.

19- WALJEE J.F., HU E.S., UBEL P.A., SMITH D.M., NEWMAN L.A. and ALDERMAN A.K.: Effect of esthetic outcome after breast-conserving surgery on psychosocial functioning and quality of life. J. Clin. Oncol., 26: 33317, 2008 .

20- MOSEWICH A.D., HADD V., PETER R.E. and ZUMBO B.D.: Invariance Testing of the SF-36 Health Survey in Women Breast Cancer Survivors: Do Personal and Cancer related Variables Influence the Meaning of Quality of Life Items? Soc. Indic. Res., 110: 559-77, 2013.

21- CUI J.: Comparative study on the effect of breast conserving surgery and modified radical operation in patients with early stage breast cancer. Biomed. Res., 28 (13): 5930-3, 2017.

22- HE Z.Y., TONG Q.S., WU G.F., LI Y., LIN H.X. and GUAN X.X.: A comparison of quality of life and satisfaction of women with early-stage breast cancer treated with breast conserving therapy Vs. mastectomy in southern China. Support Care Cancer, 20: 2441-9, 2012.

23- SO HYUN LEE, YU-SUN MIN, HO YONG PARK and TAE-DU JUNG: Health-Related Quality of Life in Breast Cancer Patients with Lymphedema Who Survived More than One Year after Surgery. J. Breast Cancer, 15 (4): 449-53, 2012

24- VAN DER STEEG A.F., De VRIES J. and ROUKEMA J.A.: Anxious personality and breast cancer. Possible negative impact on quality of life after breast-conserving therapy. World J. Surg., 34: 1453-60, 2010.

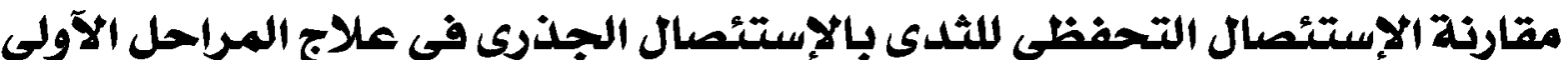

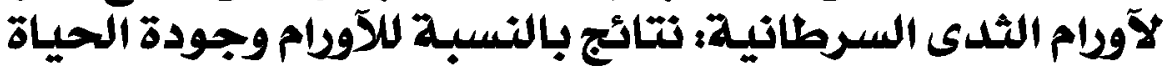

\author{
تم مقارنة الإستئمسال التحفظى اللثى مقابل الإستئمسال الجذرى اللثى الجذرى كعلاج المراحل الآلمى لآودام الثدى السرطانية، ودراسة

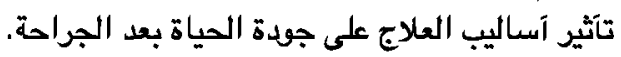

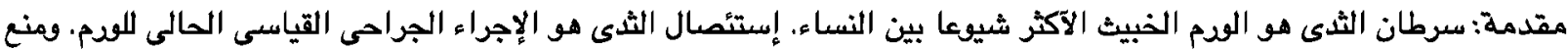

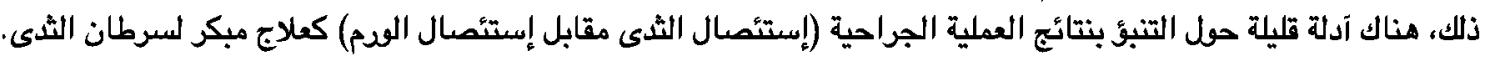

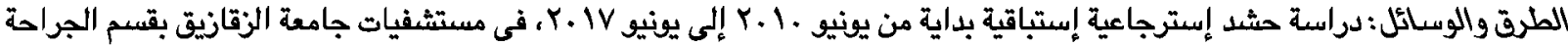

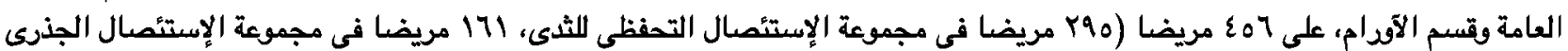

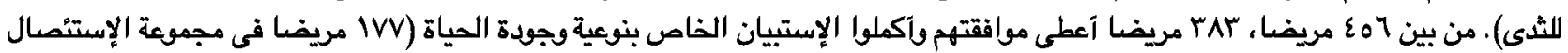

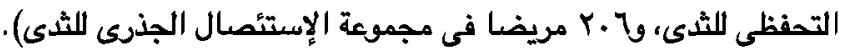

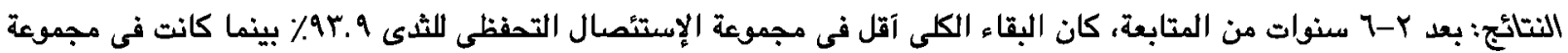

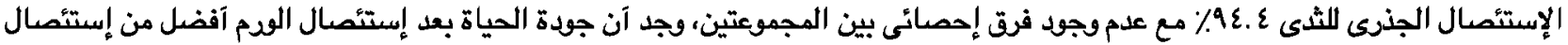
الثىى فى الوظائف الإجتماعية والعاطفية.

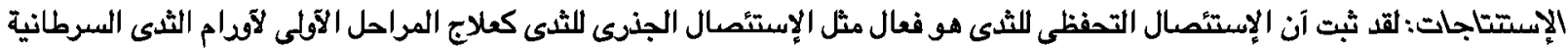

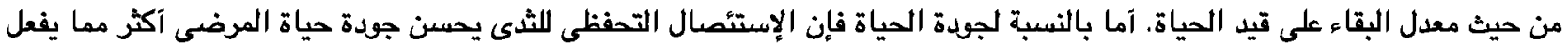
الإستئمسال الجذرى اللثىى. 